\title{
rommhalina
}

(8)

\section{Estilos de ensino}

Autor(es): $\quad$ Nobre, Paulo

Publicado por: Imprensa da Universidade de Coimbra

URL persistente:

URI:http://hdl.handle.net/10316.2/41766

DOI:

DOI:https://doi.org/10.14195/978-989-26-1286-7_5

Accessed : $\quad$ 26-Apr-2023 10:57:51

A navegação consulta e descarregamento dos títulos inseridos nas Bibliotecas Digitais UC Digitalis, UC Pombalina e UC Impactum, pressupõem a aceitação plena e sem reservas dos Termos e Condições de Uso destas Bibliotecas Digitais, disponíveis em https://digitalis.uc.pt/pt-pt/termos.

Conforme exposto nos referidos Termos e Condições de Uso, o descarregamento de títulos de acesso restrito requer uma licença válida de autorização devendo o utilizador aceder ao(s) documento(s) a partir de um endereço de IP da instituição detentora da supramencionada licença.

Ao utilizador é apenas permitido o descarregamento para uso pessoal, pelo que o emprego do(s) título(s) descarregado(s) para outro fim, designadamente comercial, carece de autorização do respetivo autor ou editor da obra.

Na medida em que todas as obras da UC Digitalis se encontram protegidas pelo Código do Direito de Autor e Direitos Conexos e demais legislação aplicável, toda a cópia, parcial ou total, deste documento, nos casos em que é legalmente admitida, deverá conter ou fazer-se acompanhar por este aviso. 
IMPRENSA DA UNIVERSIDADE DE COIMBRA

COIMBRA UNIVERSITY PRESS

RAUL A.

MARTINS

GONÇALO DIAS

PEDRO CABRAL MENDES

\section{EDITORES}

ESTRATÉGIA

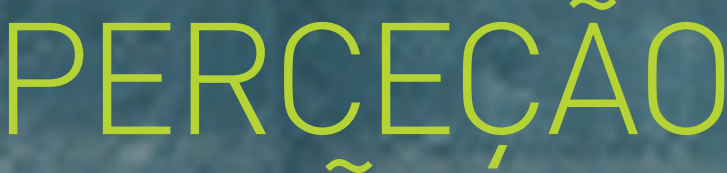

EAGÃA

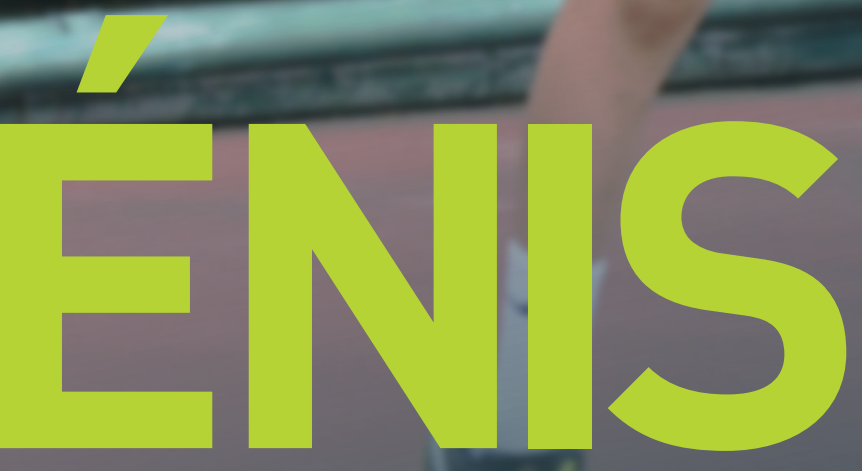




\section{CAPÍTULO 5 \\ ESTILOS DE ENSINO}

Paulo Nobre

\section{Introdução}

A natureza de um jogo condiciona a sua forma de ensino, quer se trate de uma aprendizagem de carácter essencialmente desportivo ou em ambiente escolar. O agrupamento dos jogos a partir das suas características comuns é um exercício que proporciona vantagens na definição de progressões da aprendizagem mas também no alinhamento curricular, horizontal e vertical. A classificação proposta por Ellis $(1983)^{1}$ refere-se a jogos de alvo como o golfe, de batimento como o basebol, a jogos de invasão ou territoriais como o futebol, a jogos de rede ou parede como o voleibol ou o ténis. O presente capítulo faz referência aos estilos de ensino em Educação Física e à sua utilização no ensino de um jogo de rede - o ténis. O nosso objetivo passa por proporcionar algumas linhas de reflexão sobre o estabelecimento de uma estratégia de ensino desta modalidade com recurso ao espetro de estilos de ensino de Mosston e Ashworth (1994, 2008).

Sabemos que o desenvolvimento de um currículo pode assumir diferentes configurações, consoante a perspetiva de ensino adotada,

\footnotetext{
${ }^{1}$ Apud Graça e Mesquita (2007).
} 
num continuum entre modelos curriculares centrados no ensino e modelos centrados na aprendizagem. Entendemos o conceito de currículo numa perspectiva ampla, como o conjunto de experiências de aprendizagem programadas pela escola ou outra instituição, que podem ocorrer durante, ou além, do período de contacto entre professor e aluno.

As peças estruturais a partir das quais se desenvolve o currículo dizem respeito, por um lado, aos valores que orientam e iluminam o seu desenvolvimento, dando-lhe um determinado código genético e, por outro, à posição que os vários elementos do currículo ocupam relativamente, entre si e no quadro da programação do ensino. Estes elementos são os conteúdos, as competências, os objetivos, as estratégias, as formas de organização do trabalho, o tempo, o espaço, os recursos, a avaliação.

O desenvolvimento do processo de ensino e aprendizagem implica, portanto, a definição de respostas para um vasto conjunto de questões, nomeadamente o que se pretende que os alunos aprendam, que metodologias podem ser adotadas para atingir os propósitos definidos, que sequência de aula adotar, como organizar os recursos e o grupo de alunos/atletas, como motivar os alunos e como thes dar informação de retorno, como criar um clima de interação propício a uma boa relação pedagógica, como verificar se os propósitos definidos foram atingidos, ou como verificar se as ações adotadas são congruentes com as ações realizadas e os resultados obtidos em matéria de aprendizagens.

As respostas possíveis a estas questões configuram diferentes padrões de ensino destacando-se, na literatura e no quadro da didática geral, o trabalho de Joyce e colegas (2004) ao agregar os diferentes modelos de ensino em quatro grandes famílias: modelos centrados no processamento de informação (e.g. aprendizagem significativa de Ausubel), modelos sociais (e.g. trabalho de projeto; modelos de aprendizagem democrática e socializada), modelos personalistas (e.g. 
pedagogia não diretiva de Carl Rogers) e modelos behavioristas (e.g. pedagogia por objetivos).

No âmbito específico da Educação Física, os trabalhos de Mosston (1966) e de Mosston e Ashworth (1986, 2008) ganham especial relevância sobretudo pela procura de definição de uma teoria de ensino associada a uma cadeia de decisões partilhada entre o professor e os alunos. É sobre esta teorização que nos debruçamos, centrando-nos na sua redação mais recente. Após um enquadramento e apresentação do espetro de estilos de ensino apresentamos algumas considerações sobre o uso dos estilos de ensino no ténis.

A designação 'ensino-aprendizagem' expressa uma ideia de interdependência entre ensino e aprendizagem. Neste sentido, a justaposição hifenizada dos substantivos será melhor entendida como conceito único e não somente como uma representação sequencial. O processo é hoje entendido como o resultado de um sistema dialógico, de uma ação de alguém sobre outro(s) que implica necessariamente a participação de quem ensina e igualmente uma intervenção de quem aprende, por forma a tornar sua a aprendizagem.

Esta perspetiva parece-nos útil para uma breve introdução ao trabalho de Mosston (1966) e de Mosston e Ashworth (1986, 2008). Estes autores procuraram elaborar uma teoria unificadora do ensino e da aprendizagem no âmbito da Educação Física, a partir da consideração de que o ensino é uma cadeia de decisões entre professor e aluno. As interações na aula são assim entendidas como o resultado interdependente de uma atividade de ensino e de uma atividade de aprendizagem, orientadas para a consecução de um ou mais objetivos, e a tomada de decisão torna-se o elemento central do processo de ensino-aprendizagem, podendo ser realizada pelo professor, pelo aluno ou por ambos. Desta forma, a distribuição das decisões entre quem ensina e quem aprende pode assumir diversas configurações que são tipificadas no Espetro de Estilos de Ensino de Mosston e Ashworth (2008). 
A teorização proposta pelos autores referidos atrás baseia-se num conjunto de pressupostos, nomeadamente: a tomada de decisão partilhada entre professor e aluno; a organização do espetro em onze estilos de ensino, agrupados em dois grandes grupos - os estilos de reprodução e os estilos de produção; a noção de que os objetivos de educação física se concretizam através do uso dos vários estilos de ensino e não de um ou outro em particular, não existindo estilos melhores que outros; o entendimento de que cada estilo de ensino tem uma anatomia própria, que envolve decisões de pré-impacto (antes do contacto com o aluno), de impacto (no contacto da aula) e de pós-impacto (depois da aula); a noção de que os diferentes estilos de ensino proporcionam o desenvolvimento do aluno de forma diferente, em relação aos vetores de desenvolvimento cognitivo, físico, social, emocional e ético.

Os estilos de ensino que integram o espetro definido por Mosston e Ashworth (1986, 2008) estão organizados de acordo com o grau de partilha de decisão, iniciando com estilos em que a decisão se centra no professor e evoluindo para estilos cuja decisão se centra no aluno. $O$ espetro integra o ensino por comando (A), o ensino por tarefa (B), o ensino recíproco (C), o ensino com autoavaliação (D), o ensino inclusivo (E), o ensino por descoberta guiada (F), o ensino por descoberta convergente $(G)$, o ensino de produção divergente $(\mathrm{H})$, o programa individual desenhado pelo aluno (I), o ensino iniciado pelo aluno $(\mathrm{J})$ e o autoensino $(\mathrm{K})$. Os estilos de (A) a (E) são estilos de reprodução e orientam-se maioritariamente para a reprodução do conhecimento adquirido; os estilos de (F) a (K) são estilos de produção que se orientam para a produção de conhecimento novo pelo aluno. Cada estilo de ensino assume um conjunto de características específicas, potenciando particularmente cada um dos vetores de desenvolvimento.

No ensino por comando o propósito é promover uma aprendizagem exata da(s) tarefa(s), num curto período de tempo, sendo todas as decisões tomadas pelo professor. O aluno segue as ordens do 
professor e desempenha a tarefa quando e como descrita, recebendo feedback do professor acerca do seu papel e da aprendizagem realizada. Este estilo de ensino permite manter o grupo de treino organizado, promovendo um alto empenho na tarefa e um progresso rápido, orientado para o uso eficiente do tempo.

$\mathrm{O}$ ensino por tarefa permite dar tempo ao aluno/atleta para trabalhar individualmente na tarefa, com o grupo distribuído em diferentes tarefas, e possibilitando ao professor o fornecimento de feedback individualizado. Ao aluno cabe realizar a tarefa e decidir sobre a sua ordem, os tempos, o ritmo. Com este estilo, os alunos começam a ter alguma independência e o tempo da tarefa pode ser afetado de acordo com as suas decisões.

$\mathrm{O}$ ensino recíproco caracteriza-se pelo trabalho em pares, de um aluno com um parceiro, a quem fornece feedback de acordo com critérios preparados pelo professor. O aluno seleciona os papéis de executante e de observador. O executante desempenha a tarefa e o observador compara o desempenho do colega com os critérios e dá-lhe feedback. Quando termina, trocam de papéis. O professor controla e fornece feedback aos observadores, respondendo às suas questões. Este estilo permite uma participação mais ativa do aluno, nomeadamente nos vetores cognitivo e social, não exigindo a presença permanente do professor.

No ensino com autoavaliação, o aluno aprende a realizar uma tarefa e verifica o seu próprio trabalho. Ao desempenhar a tarefa, toma algumas decisões e verifica o seu desempenho de acordo com critérios estabelecidos pelo professor, que lhe fornece feedback no final. Com este estilo os alunos conhecem os seus limites e sucessos e, embora a autoavaliação seja muitas vezes privada, realizam uma aprendizagem suplementar de controlo avaliativo da sua aprendizagem.

O ensino inclusivo orienta-se para uma promoção do sucesso individual, dando possibilidade a que o aluno experimente o seu êxito, de acordo com o seu nível de proficiência. A aula é organizada 
por níveis de dificuldade e o aluno aprende a selecionar um nível ou tarefa que é capaz de desempenhar. Além das decisões definidas no ensino por tarefa, o aluno examina os diferentes níveis da tarefa, seleciona o nível apropriado para si, realiza a tarefa e compara o seu desempenho com os critérios preparados pelo professor. $\mathrm{O}$ aluno pode recorrer ao professor para o esclarecimento de dúvidas e pode optar por um nível anterior, ou menos complexo, para experimentar sucesso. O professor prepara as tarefas, os seus níveis e os respetivos critérios. Quando necessário assiste o aluno nas opções a tomar, designadamente quando este apresenta dificuldade em selecionar o nível inicial ou alternativo.

O propósito do ensino por descoberta guiada é o de fazer o aluno descobrir um conceito, respondendo a uma sequência de questões ou pistas lançadas pelo professor. O aluno procura encontrar a resposta para cada questão ou pista na sequência, de forma a descobrir a resposta final. Ao professor compete desenhar uma sequência de questões, orientadas para pequenas descobertas e apresentar as questões de forma sequenciada, retroalimentando periodicamente o aluno em relação à descoberta do conceito ou desempenho pretendido. Este estilo de ensino exige uma elevada preparação por parte do professor e dado o esforço cognitivo associado, pode originar um menor empenho físico do aluno.

O ensino por descoberta convergente tem como propósito promover a descoberta, pelo aluno, de uma solução para um problema, para clarificar algo ou chegar a uma conclusão, empregando procedimentos lógicos. O aluno examina o problema ou situação, desenvolve um procedimento para o solucionar ou chegar a uma conclusão, verifica o processo e a solução de acordo com critérios apropriados. O professor apresenta o problema ou situação a resolver, acompanha o processo de pensamento do aluno e fornece feedback ou pistas sem indicar a solução final. Este estilo é muito exigente para o professor na preparação das atividades. 
No ensino de produção divergente procura-se igualmente solucionar um problema, mas agora pela descoberta de várias respostas. O propósito consiste em levar o aluno a descobrir e a produzir várias respostas para uma questão específica. O aluno produz diversas respostas para uma única questão, aferindo a sua validade e verificando as respostas em relação a outras tarefas relacionadas. O professor define a questão a colocar e avalia as respostas, fornecendo feedback sobre as soluções encontradas. Este estilo é igualmente exigente para o professor, quer no domínio dos conteúdos trabalhados, quer na preparação e condução das atividades de aprendizagem.

No programa individual desenhado pelo aluno, o propósito é o de levar o aluno a desenhar, desenvolver e desempenhar uma série de atividades organizadas num programa pessoal. O aluno seleciona o foco do seu estudo, identifica e organiza as questões apropriadas, organiza as tarefas e desenha um programa pessoal de aprendizagem. O programa pode envolver uma recolha de informação, que é organizada de acordo com um quadro de referência, de modo a encontrar respostas para as questões formuladas inicialmente. Os procedimentos são verificados de acordo com critérios intrínsecos à matéria em estudo. Ao professor cabe indicar uma área geral a partir da qual o aluno seleciona o tópico a estudar e acompanhar o progresso do aluno. Neste estilo de ensino é necessária experiência prévia do aluno.

Os dois últimos estilos de ensino do espetro remetem para formas de aprendizagem particularmente autónomas e em que o espaço de decisão do professor é quase ausente ou meramente consultivo. O propósito do ensino iniciado pelo aluno consiste em iniciar o aluno na responsabilidade de conceção total de um programa de aprendizagem. Cabe ao aluno conduzir o ensino e a aprendizagem, com um acompanhamento do professor, se solicitado. O autoensino baseia-se na vontade de autoaprendizagem do aluno, que se ensina a si mesmo. É um estilo de ensino que dispensa a presença do professor, sendo difícil de aplicação em contexto escolar formal. 


\section{Estilos de ensino no ténis}

A perspetiva a partir da qual olhamos o ténis neste artigo orienta-se para um modelo centrado na aprendizagem, baseado no jogo como forma de dar significado à aprendizagem do aluno ou atleta. Não excluindo obviamente outras leituras, valorizamos a abordagem Play and Stay no ensino do ténis, uma proposta metodológica da Federação Internacional de Ténis em que o jogo é a base de uma aprendizagem em três etapas, condicionadas por três fatores: o espaço de jogo, as bolas e as raquetes (Federação Portuguesa de Ténis, 2010).

A posição do corpo, o jogo de pés, os efeitos (topspin, underspin, sidespin), o serviço, os batimentos de esquerda ou de direita, o vólei, o smash, o lob, o amorti são elementos que ganham significado no jogo. Aprender a jogar ténis, jogando, poderá assim ser potenciado por uma abordagem prática orientada para a resolução de problemas em contexto real, onde as técnicas e as táticas adquirem valor de uso e se transformam em aprendizagens profundas e significativas, ainda que não se excluam abordagens complementares de natureza mais analítica no âmbito do treino motor, se efetivamente necessárias e curricularmente válidas.

Uma abordagem desta natureza afasta-se das limitações de uma estratégia única ou baseada num só estilo de ensino. O estudo realizado por Hewitt e Edwards (2011) envolvendo 165 treinadores de ténis revelou, contudo, um uso maioritário dos estilos de reprodução, sendo predominante o uso do ensino por tarefa no treino do ténis.

Como nenhum estilo serve todas as situações de aprendizagem, espera-se que um professor ou treinador eficaz tenha a capacidade de mudar, combinar e realizar a transição entre diferentes práticas de ensino durante as sessões. Nessa perspetiva, a competência dos professores revela-se não apenas no domínio do conjunto de ferramentas disponíveis para o ensino, no caso o reportório de estilos de ensino, mas sobretudo na capacidade da sua mobilização 
estratégica em função do contexto de aprendizagem. Hewitt (2015), no seu trabalho sobre a utilização dos estilos de ensino por treinadores de ténis, destaca a necessidade de melhorar a formação neste domínio, nomeadamente no conhecimento e compreensão sobre a variedade de estilos de ensino e na definição dos conceitos pedagógicos associados ao uso de estilos de ensino no ténis.

A lógica do Play and stay indica um caminho de trabalho com estilos de ensino combinados, utilizando estilos de produção em conjunto com estilos de reprodução. A base, na perspetiva do modelo Play and stay, é próxima da lógica de um ensino do jogo para a sua compreensão (Bunker \& Thorpe, 1982), partindo daí e de um trabalho de resolução de problemas práticos e reais de jogo, com a adaptação de variáveis que incluem as dimensões do campo, as redes, as bolas, mas também as necessidades de aprendizagem dos atletas ou dos alunos. Neste sentido, a promoção de uma aprendizagem pragmática da modalidade ou matéria seria favorecida pelo uso de estilos de ensino como a aprendizagem por descoberta guiada, o ensino recíproco ou o ensino com autoavaliação.

O ensino por descoberta guiada, apesar de exigir uma preparação específica, permite ao professor conduzir a aprendizagem do aluno, fornecendo-lhe as pistas de acordo com a sua própria evolução na aprendizagem. Inclui uma componente cognitiva considerável e embora seja mais limitativo em termos de aprendizagem implícita do que a aprendizagem por descoberta (Reid e col., 2007), permite obter melhorias de desempenho mais rápidas no ténis, sendo eficaz quando o período de treino é limitado (Smeeton e col., 2005).

$\mathrm{O}$ ensino recíproco apresenta igualmente vantagens do ponto de vista da aprendizagem dos alunos. Estas referem-se a evidências de um desempenho superior em diversas tarefas motoras, à qualidade do feedback fornecido pelos observadores, que é usualmente adequado e entendido como relevante pelo executante, e ainda ao facto de a prática nas condições do ensino recíproco facilitar a aprendizagem 
de pistas essenciais para a melhoria do desempenho pelos alunos (Byra, 2006). O ensino recíproco permite ainda uma aprendizagem do domínio cognitivo que nos parece relevante para um desporto com a natureza do ténis; a aprendizagem procede também através de um juízo avaliativo realizado entre um desempenho que o observador sabe ideal, de acordo com os critérios fornecidos, e um desempenho real que é por si observado e sobre o qual precisa de emitir um feedback apropriado e válido. Acresce que em seguida executará a mesma tarefa e aqui poderíamos falar de uma aprendizagem tripla, a partir da observação vicariante, do juízo e da sua prática.

A importância do autoensino explica-se igualmente pela natureza do jogo do ténis. No estudo de Patinanoglou e colaboradores (2008), foram comparados os efeitos da utilização dos estilos de ensino por comando e autoavaliação, tendo sido verificado que os alunos do grupo do estilo de autoavaliação apresentavam um melhor desempenho motor e atitudes mais positivas em relação ao ténis, em comparação com os colegas do grupo de ensino por comando.

\section{Conclusão}

Considerando que entendemos que o ensino deverá adaptar-se de modo a processar-se de acordo com as características dos aprendentes, incluindo a personalidade, cremos ser possível e desejável uma utilização de estilos de ensino diversificada ao longo da progressão do ensino. A existência de diferentes estilos de aprendizagem nos grupos ou turmas com que trabalhamos justifica precisamente essa necessidade. A seleção de um estilo de ensino não deveria ser descontextualizada das formas de aprender com que estamos a trabalhar. Existem indivíduos que aprendem melhor ouvindo (auditivos), outros visualizando (visuais), outros fazendo (pragmáticos, cinestésicos) e

é possível observar diversas matrizes a partir destes três estilos de 
aprendizagem. Sendo no quadro desta diversidade que se processa o ensino de uma modalidade como o ténis, a realização de um diagnóstico das formas de aprender dos nossos atletas ou alunos assume uma importância fundamental, quer para a definição do(s) de estilo(s) de ensino a adotar, quer para o modo de instrução ou tipo de feedback a utilizar. Ao pretendermos o sucesso de todos na aprendizagem, este diagnóstico e o alinhamento de uma estratégia de ensino congruente afiguram-se-nos como ações fundamentais para que o ensino seja eficaz, no ténis como em qualquer outra modalidade.

\section{Bibliografia}

Bunker, D., \& Thorpe, R. (1982). A model for the teaching of games in secondary schools. Bulletin of Physical Education, 18, 5-8.

Byra, M. (2006). The reciprocal style of teaching: A positive motivational climate. In AIESEP World Congress - The Role of Physical Education and Sport in Promoting Physical Activity and Health. Jyväskylä.

Federação Portuguesa de Ténis (2010). Manual de Ténis na Escola. Linda-a-Velha: Federação Portuguesa de Ténis.

Graça, A., \& Mesquita, I. (2002). A investigação sobre o ensino dos jogos desportivos: ensinar e aprender as habilidades básicas do jogo. Revista Portuguesa de Ciências do Desporto, 2, 67-79.

Hewitt, M. (2015). Teaching Styles of Australian Tennis Coaches: An exploration of practices and insights using Mosston and Ashworth's Spectrum of Teaching Styles (Doctoral Thesis). School of Linguistics, Adult and Specialist Education Faculty of Business, Education, Law and Arts: The University of Southern Queensland.

Hewitt, M., \& Edwards, K. (2011). Self-identified teaching styles of junior development and club professional tennis coaches in Australia. Coaching and Sport Science Review, 55, 6-8.

Patinanoglou, K., Mantis, N., Digelidis, N., Tsigilis, N., \& Papapetrou, L. (2008). The Command and Self-Check Styles for more Effective Teaching of Tennis at the Elementary School. International Journal of Physical Educution, 45, 26-32.

Reid, M., Crespo, M., Lay, B., \& Berry, J. (2007). Skill acquisition in tennis: Research and current practice. Journal of Science and Medicine in Sport, 10, 1-10.

Smeeton, N., Williams, A., Hodges, A., \& Ward, P. (2005). The Relative Effectiveness of Various Instructional Approaches in Developing Anticipation Skill. Journal of Experimental Psychology: Applied, 11, 98-110. 